\title{
"UM APÓLOGO - MACHADO DE ASSIS" - DO ESCRITOR SINGULAR AO BRASILEIRO EXEMPLAR ${ }^{1}$
}

\author{
Hélio de Seixas Guimarães \\ Universidade de São Paulo / CNPq \\ São Paulo (SP), Brasil
}

\begin{abstract}
Resumo: O artigo trata do processo de construção da figura de Machado de Assis na década de 1930, focalizando a primeira adaptação de uma obra sua para o cinema - "Um apólogo - Machado de Assis", baseado no conto "Um apólogo", produzido em 1939 pelo Instituto Nacional de Cinema Educativo (INCE), com direção de Humberto Mauro e participações de Lúcia Miguel Pereira e Edgard Roquete Pinto. O curta-metragem sintetiza o processo de transformação do escritor singular e estrangeirado, visão até então predominante entre os críticos, no homem brasileiro exemplar, intérprete da alma brasileira, em consonância com os novos papéis prescritos pelo Estado Novo para a literatura e o literário.
\end{abstract}

Palavras-chave: "Um apólogo"; adaptação; cinema; história cultural; Estado Novo.

\section{"Um apólogo - Machado de Assis" - brom the singular writer to the exemplary Brazilian}

\begin{abstract}
The article examines the construction of the modern figure of Machado de Assis during the 1930's, focusing on the first film adaptation of one of his works - "Um apólogo - Machado de Assis", produced in 1939 by the Instituto Nacional de Cinema Educativo (National Institute of Educational Film, INCE), directed by Humberto Mauro, with the participation of Lúcia Miguel Pereira and Edgard Roquete Pinto. The short motion picture, the article argues, epitomizes the transformation of the unique man and writer, seen up to that point as one of a kind, into an exemplary Brazilian man, the writer of the Brazilian soul, attuned with the new roles prescribed by the Estado Novo (1937-1945) to literature and the literary.
\end{abstract}

Keywords: "Um apólogo"; adaptation; film; cultural history; Estado Novo.

\footnotetext{
${ }^{1}$ Uma primeira versão deste texto, que integra pesquisa realizada com financiamento de Bolsa de Produtividade em Pesquisa do CNPq, foi apresentada no XXVIII Congresso Internacional da Latin American Studies Association (LASA), realizado no Rio de Janeiro em junho de 2009.
} 
Na década de 1930, produz-se uma transformação radical na visão até então dominante sobre a obra de Machado de Assis e a figura do escritor. Isso tem a ver com o trabalho de uma notável geração de críticos - entre eles Augusto Meyer, Mário Matos, Astrojildo Pereira e Lúcia Miguel Pereira -, como já observado por Antonio Candido: "não há dúvida de que foi desses estudos e alguns outros, geralmente precedendo ou sucedendo de pouco as comemorações do centenário do nascimento em 1939, que começou a compor-se a nossa visão moderna". ${ }^{2}$

A visão moderna refere-se aos fenômenos de ambiguidade e aos aspectos turvos da obra, cuja complexidade foi ressaltada pelos leitores críticos, que retiraram Machado de Assis do lugar quase inofensivo de escritor absenteísta, ironista ameno e estilista impecável. Surge o monstro cerebral, o romancista do Segundo Reinado, o analista profundo de fenômenos psicossociais. Em paralelo a isso, o homem singular e o escritor estrangeirado, até então vistos como espécie de acidente na evolução da literatura nacional, são transformados em homem brasileiro exemplar e grande analista da alma brasileira. ${ }^{3}$

Todo esse processo está intrinsicamente relacionado com a modernização cultural e as turbulências políticas da década de 1930, culminando com as comemorações do centenário de nascimento, patrocinadas pelo Estado Novo, em grande parte responsável pela elaboração e fixação dessa nova figura machadiana.

A eficácia e a permanência da figura machadiana forjada naquele momento certamente estão relacionadas ao modo de operação do Estado Novo, cujas iniciativas no âmbito da cultura se deram em várias frentes e de modo bastante articulado: $1^{\circ}$ ) no campo da educação, com a promoção de reformas educacionais e produção de materiais didáticos que incentivavam o culto aos ícones da nacionalidade, os chamados "vultos nacionais"; $2^{\circ}$ ) no campo da comunicação, que também busca difundir em novos meios, especialmente o rádio e o cinema, informações sobre personalidades históricas que de

\footnotetext{
${ }^{2}$ CANDIDO, Antonio. Esquema de Machado de Assis. In: Vários escritos. São Paulo: Duas Cidades, 1970. p. 21.

3 "Homem representativo" e "nacionalista" são alguns dos epítetos que Austregésilo de Athayde emprega em títulos de uma série de artigos que publicou no Diário da Noite em junho de 1939.
} 
certa maneira antecipariam valores promovidos pelo Estado Novo; e $3^{\circ}$ ) no campo da cultura, na medida em que se começam a formular e promover políticas relativas ao patrimônio histórico e cultural, por meio da criação do Serviço do Patrimônio Histórico e Artístico Brasileiro, então SPHAN, órgão que está na origem do atual IPHAN.

A convergência entre educação, comunicação e cultura com vistas à criação e difusão das novas ideias de Brasil e de brasilidade que se forjaram durante o Estado Novo encontraram uma espécie de síntese na ação do Instituto Nacional de Cinema Educativo, o INCE. Criado em 1936, tendo à frente Edgard Roquete Pinto e Humberto Mauro, o órgão também era subordinado ao Ministério da Educação e Saúde, chefiado por Gustavo Capanema de 1934 a $1945 .{ }^{4}$ O INCE teve papel importante no processo de institucionalização e patrimonialização da cultura de maneira geral, da literatura em particular, e de Machado de Assis, em especial.

Como procuro mostrar neste artigo, a adaptação do conto "Um apólogo" para o cinema, na versão que Humberto Mauro dirigiu para o Instituto Nacional de Cinema Educativo, em 1939, é exemplar de todo esse processo.

Trata-se do primeiro texto de Machado de Assis adaptado para o meio audiovisual. Vale notar que, tecnicamente, isso já poderia ter ocorrido muito antes, uma vez que se produzia cinema no Brasil desde os últimos anos do século XIX. No período entre 1908 e 1912, definido por Paulo Emílio Salles Gomes como "época de ouro", muitos filmes recorreram a autores e livros do século 19 para elaborar seus enredos. Nesse período, José de Alencar foi autor muito adaptado, e $O$ guarani teve pelo menos três versões, ao passo que até a década de 1930 Machado não teve qualquer de suas obras levadas ao cinema. ${ }^{5}$

A ausência de Machado da lista dos escritores adaptados ou mais adaptados certamente tem muitas razões (mesmo posteriormente, com a televisão, são poucas as obras adaptadas, e elas se resumem aos romances da chamada primeira fase, com a exceção recentíssima de Dom Casmurro, que ganhou a primeira versão para a TV em

\footnotetext{
${ }^{4}$ Sobre a atuação do Ministério da Educação e Saúde e Gustavo Capanema, ver Robert M. Levine. Pai dos pobres? O Brasil e a era Vargas. São Paulo: Companhia das Letras, 2001.

${ }^{5}$ Há registro de uma versão anterior de "Um apólogo", realizada pelo próprio INCE e datada de 1936, da qual não restou cópia.
} 
2008, por ocasião das comemorações do centenário de morte do escritor). ${ }^{6}$ Além das dificuldades colocadas pela complexidade do texto machadiano, considerado pouco acessível ao público leitor, e ainda menos acessível ao público ampliado do cinema, a chegada tardia ao filme pode estar relacionada também ao relativo ostracismo em que ficaram o escritor e sua obra ao longo das décadas de 1910 e $1920{ }^{7}$

"Um apólogo - Machado de Assis" também é o primeiro de uma série de filmes, que, no conjunto, compõem uma galeria audiovisual de "vultos nacionais", ${ }^{8}$ o que inclui heróis individuais, como Carlos Gomes, Euclides da Cunha, Gonçalves Dias, o barão do Rio Branco e o próprio Machado, e também heróis coletivos, como os bandeirantes e os inconfidentes. Numa segunda fase do INCE, que começa em 1947, o panteão passaria a incluir também Martins Pena (1947), Castro Alves (1948), Rui Barbosa (1949) e Alberto Nepomuceno (1950), entre outros. ${ }^{9}$ Assim como ocorreu com Um apólogo, realizado no contexto das comemorações do centenário de nascimento de Machado de Assis, em 1939, a produção desses outros filmes seguia o calendário das efemérides nacionais.

Num estudo provocativo, intitulado Literatura não é documento, Ana Cristina César associa ao Estado Novo o primeiro movimento organizado de produção de uma mitologia do autor literário, que se tornaria elemento importante para a constituição de personalidades, em grande medida mitos, capazes de personificar os grandes "valores

\footnotetext{
${ }^{6}$ As adaptações de textos literários para a televisão, com atenção às obras de Machado adaptadas entre as décadas de 1950 e 1990, são assunto da dissertação de mestrado que defendi na Unicamp em 1995, intitulada Literatura em televisão - uma história das adaptações de textos literários para programas de $T V$.

${ }^{7}$ Ao percorrer o que se escreve sobre Machado nos jornais de 1939, por ocasião das comemorações do centenário de nascimento, o estudioso frequentemente encontra menções ao esquecimento em que Machado teria caído desde sua morte, em 1908, até os anos 30, quando homem e obra despertam grande atenção de biógrafos e críticos.

${ }^{8}$ O filme estreou em cinemas do Rio de Janeiro em 14 de julho de 1939, com "sessões gratuitas dedicadas ao povo" no dia 16, no cine Odeon. Cf. "A agulha e a linha - Será exibido, a começar de hoje, o excelente film do I.N.C.E.". $O$ Globo, 14.07.1939. Na imprensa da época, há muitos elogios ao filme, referido como "um filme brasileiro que para ser considerado bom dispensa a nossa benevolência e quaisquer perniciosas considerações de protecionismo", como saiu em $O$ Globo em 7 de julho de 1939; ou como "uma autêntica obra-prima, um lavor cinematográfico que parece saído de um estúdio norte-americano ou europeu", como publicado em A Noite em 30 de junho de 1939.

${ }^{9}$ Cf. SCHVARZMAN, Sheila. Humberto Mauro e as imagens do Brasil. São Paulo: Editora Unesp, 2004. p. 310-311.
} 
nacionais". Nesse estudo, Ana Cristina César define o modo de apropriação do "literário" pelos filmes do INCE, em sua grande maioria dirigidos por Humberto Mauro:

A apreensão do literário por esses filmes, filtrada pelos critérios das concorrências, tenderia a se identificar com a visão oficial da literatura, e mais, com a concepção oficial sobre a cultura; exaltação da personalidade do escritor e preocupação em fixar para a posteridade a imagem do vulto e dos fetiches que marcam sua presença ("registro da memória nacional"): berço, túmulo, objetos pessoais, iconografia familiar, caminhos que percorreu, tipos que conheceu, capas dos seus livros, prêmios recebidos, aclamações, belos bustos em bronze. ${ }^{10}$

Os perfis de intelectuais, escritores e tipos nacionais aparecem ao lado de filmes sobre "acontecimentos de projeção nacional", tais como o Dia da Bandeira, o Dia da Pátria, e também de documentários sobre botânica, medicina, saúde pública etc. $\mathrm{O}$ cinema compunha à sua maneira a Enciclopédia Brasileira que Mário de Andrade fora encarregado de coordenar no mesmo período para o INL - o Instituto Nacional do Livro, dirigido por Augusto Meyer -, projeto que não seria levado a cabo.

Para a produção de "Um apólogo", contribuíram intelectuais e artistas das mais diferentes áreas, o que dá ideia do enorme investimento feito nessa produção. A narração é do médico e antropólogo Edgard Roquete Pinto; a biógrafa e crítica Lúcia Miguel Pereira é autora da nota biobibliográfica que introduz o filme, além de aparecer em cena com um livro na mão, dando início e concluindo a narração do conto, fazendo as vezes de narradora do conto machadiano; os desenhos que ilustram cenas das principais obras de Machado são de autoria de Santa Rosa, o célebre artista que também ilustrou os livros de Graciliano Ramos; a partitura é do maestro J. Otaviano; e a direção é de Humberto Mauro, frequentemente aludido como o "mais brasileiro" entre os diretores do cinema nacional. ${ }^{11}$ Com 14 minutos, o filme consiste basicamente em duas partes muito diferentes entre si do ponto de vista da narração, mas que, como veremos, acabam perfeitamente conjugadas.

\footnotetext{
${ }^{10}$ CÉSAR, Ana Cristina. Literatura não é documento. Funarte: Rio de Janeiro, 1980. p. 11.

${ }^{11}$ Cf. SCHVARZMAN, Sheila. Humberto Mauro e as imagens do Brasil, cit., p. 15.
} 
A primeira parte consiste na notícia biobibliográfica de Machado de Assis, na qual a locução de Roquete Pinto destaca os pontos principais da vida e da obra do escritor, ao mesmo tempo em que são mostradas imagens de lugares, objetos e livros relacionados a ele. A segunda parte do "short", como então se denominavam os curtasmetragens, consiste na adaptação do conto propriamente dita, com atores e atrizes interpretando os diálogos em que a linha e a agulha disputam a primazia num cenário que reconstitui realisticamente o interior de uma caixa de costura, onde estão situadas as personagens principais e também o alfinete, que só aparece no final.

Assim, o filme lança mão tanto de recursos documentais como ficcionais, predominando o documentário na primeira parte e a dramatização, na segunda.

A narração da parte inicial do filme, como era comum nas produções do INCE, é feita em tom elevado, o que lhe dá um quê de "narrativa épica", protagonizada pelos tão decantados vultos nacionais, de que as ditaduras brasileiras sempre gostaram tanto, e que seriam elementos fundamentais para a constituição de uma "épica nacional", como destacou Sheila Schvartzman no seu estudo sobre Humberto Mauro. ${ }^{12}$

Na porção ficcional, o filme se mantém bastante rente ao texto do conto, com atores e atrizes caracterizados, interpretando a agulha, a linha e o alfinete. Os diálogos das personagens são quase inteiramente preservados, com modificações pouco significativas aqui e ali. Entretanto, os trechos do narrador são suprimidos, à exceção do "era uma vez" inicial, e do parágrafo final, que contém a moral da história ("Contei esta história a um professor de melancolia, que me disse, abanando a cabeça: - Também eu tenho servido de agulha a muita linha ordinária!"), ambos lidos por Lúcia Miguel Pereira. A presença da biógrafa e crítica, à época em grande evidência por conta da publicação do seu Machado de Assis - estudo crítico e biográfico, de 1936, dava credibilidade tanto às informações biográficas como à adaptação do conto propriamente dita. Além disso, a figura feminina e professoral adequava-se perfeitamente aos propósitos didáticos do filme.

Algumas partes do conto, sobretudo aquelas mais descritivas, atribuídas ao narrador, foram suprimidas na versão fílmica. As informações contidas nesses trechos são fornecidas pelas imagens acompanhadas de música, sem diálogos, que mostram a

${ }^{12}$ Idem, p. 267. 
baronesa, o barão e a criada-costureira nos preparativos para um baile, a chegada da noite de festa etc. etc.

Tudo isso permite ao filme concentrar-se na disputa entre a linha e a agulha, entre quem realmente faz "o trabalho obscuro e ínfimo" e quem de fato recebe os louros, entre quem trabalha e quem brilha. Esse conflito, central nas duas narrativas, parece ganhar conotações trabalhistas na versão cinematográfica. Tudo ali parece concorrer para a celebração da operosidade e do trabalho, mesmo quando isso é feito às avessas, ironicamente, já que o filme, assim como o conto, mostra explicitamente que quem trabalha não é quem aparece, chamando a atenção para a injustiça contra aqueles que servem de escada para que espertos e exploradores brilhem nos salões da alta sociedade.

A grande diferença é que essa situação, no filme, é explicitamente localizada no passado, o que fica indiciado pelos figurinos das personagens e pelas referências ao tempo das baronesas, quando apenas a linha ia aos bailes. A localização no passado fica indiciada também pela referência ao autor já morto, de outro tempo e outro século Machado de Assis -, já configurado como estátua na primeira parte do filme. E também pela música, descrita por um cronista da época como "uma daquelas valsas voluptuosas que se dançavam nos salões da monarquia". ${ }^{13}$ Tudo isso parece sugerir que aquele estado de coisas estaria superado no presente republicano e na nova ordem instituída pelo Estado Novo, de valorização do esforço individual e reconhecimento do trabalho. O filme parece alertar o espectador de que já se foi o tempo dos barões, baronesas e mucamas; de que a exploração incontrastada e incontrastável dos subalternos é coisa do antigo Estado.

Ao mesmo tempo em que a matéria narrativa propõe um contraponto entre a injustiça do passado e a reparação que se quer fazer no presente, visto como superação do passado, o filme busca identificar no passado, e sobretudo na figura do homem e do escritor, valores como a modéstia, a tenacidade, o esforço e a dedicação ao trabalho, que deverão ser cultuados e perseguidos pelo brasileiro comum e sobretudo pelos futuros cidadãos prestantes da pátria, os escolares a quem o filme se dirige preferencialmente. Machado de Assis torna-se, portanto, um homem exemplar. Nas palavras de Roquete

13 "A transfiguração de um apólogo", de Carlos Maul. Correio da Manhã, 13.07.1939. 
Pinto, apresentadas na porção biobibliográfica do filme, "como homem e como artista, [Machado de Assis] representa para os brasileiros um alto e puro exemplo."

Aqui começa a ficar claro - espero - o porquê de ser justamente um apólogo, narrativa de fortes conotações morais e moralizantes - algo aliás tão pouco típico da produção machadiana -, que serviu de matéria para a primeira versão de uma obra de Machado de Assis para o cinema. Certamente concorreu para isso o fato de ser essa uma das narrativas machadianas mais vulgarizadas nas antologias escolares. Também é certo que havia nisso algum cálculo sobre a fácil legibilidade e compreensão desse tipo de narrativa pelo público escolar e de massa almejado pelas produções do INCE, exibidas em salas de cinema, para o grande público, mas voltadas principalmente para o ambiente escolar.

O cinema produzido pelo INCE é um cinema exemplar, para o qual o apólogo caía como uma luva. Se as duas partes do filme têm características muito diversas e diferenças muito marcadas, é justamente o tom apologal que lhes dá organicidade. Isso fica sugerido já pelo título, "Um apólogo - Machado de Assis", no qual a justaposição dos dois termos, separados por travessão, parece sugerir que Machado de Assis, o nome, já é, em si, um apólogo. Não há subordinação de um termo a outro, mas sim um paralelismo, o que sugere equivalência entre os termos, de modo que Machado de Assis, sua vida e sua obra podem e devem ser entendidos pelo espectador como um apólogo.

O tom moralizante da historieta rebate, portanto, sobre o intróito biobibliográfico (e vice-versa), também construído em tom de apólogo, na medida em que encerra uma lição de moral - e social - muito clara: a de que é possível, no Brasil, nascer pobre e chegar à consagração e à frequentação dos salões mais prestigiosos do país. Possibilidade que Machado encarnaria muito bem, tendo percorrido os dois polos da sociedade brasileira, saindo do morro do Livramento e chegando à Academia Brasileira de Letras.

Essa movimentação entre polos sociais é reiterada pelo filme, no qual palavras e imagens repetidamente reforçam a movimentação entre planos verticais. Já na abertura biobibliográfica, são várias as sequências de imagens de crianças se movimentando pelas ruelas do morro do Livramento, numa clara evocação à figura de Machado como um moleque de morro, tão enfatizada por Lúcia Miguel Pereira em seu Estudo crítico e 
biográfico. As imagens fazem contraste com a cidade lá embaixo, onde se eleva, imponente, o prédio da Academia Brasileira de Letras. Morro do Livramento e Academia: emblemas dos altos e baixos da cidade percorridos pelo escritor, que por sua vez se tornam signos da ascensão social possível. Também na parte francamente ficcional, vemos já na primeira cena a criada da baronesa subindo as escadas de uma mansão no alto de um morro do Rio de Janeiro, a partir do qual se vê, abaixo e ao longe, a baía de Guanabara. Esse movimento de sobe e desce será repetido mais duas vezes pela criada, ocupada em mostrar à baronesa o modelo do vestido que costura para que esta brilhe na noite do baile.

A hierarquização entre agulha e linha, que alimenta o conflito da história, se reproduz na relação entre a criada e a baronesa. O paralelismo é reforçado, no filme, pela intercalação entre sequências ambientadas na caixinha de costura, protagonizadas pela linha e pela agulha, e as sequências ambientadas na luxuosa casa dos barões, mobiliada ao gosto imperial, e protagonizadas pela criada e pela baronesa.

O momento de encontro entre esses dois planos ficcionais se dá quando, após assistirmos à acirrada discussão entre linha e agulha, vemos a criada recorrer à linha e à agulha, que a espeta. A sugestão é de vingança da agulha contra a criada, já que a agulha nada pode fazer contra sua inimiga, a linha. Em seguida, vemos em close a dificuldade da criada para enfiar a agulha na linha, sugerindo a dificuldade em harmonizar as duas partes em litígio.

Depois de várias tentativas frustradas, a criada recorre aos óculos - e é só quando os coloca que conseguirá unir linha e agulha para a realização do trabalho que tem de ser feito. Fica aí a sugestão de que é preciso mudar a ótica, ajustar a visão, de modo a promover a conciliação entre os interesses da agulha e da linha, das classes trabalhadoras e das classes ociosas, para a promoção de alguma harmonia social. Essa harmonia, no entanto, se dá à custa da frustração da agulha, que fica na caixa de costura, e da realização apenas vicária da criada, que trabalha, mas também não desfruta do baile. Se agulha e criada são figuras correlatas, uma diferença marcante entre elas questão de óculos? - está no fato de assistirmos à frustração da agulha, triste e solitária na caixa de costura, ao passo que a criada em nenhum momento lamenta o fato de não ir ao baile. Parece haver, portanto, um deslocamento da questão, uma transformação da 
disputa primitiva entre linha e agulha (que é da mesma natureza das divergências entre a cigarra e a formiga, entre Cinderela e suas irmãs), na medida em que a criada de alguma forma entende a necessidade da harmonização e reconhece o seu lugar, dominando os impulsos primitivos da inveja, do egoísmo e da vaidade, motores principais das personagens da fábula.

E o alfinete? Tanto no conto como no filme, ele comparece no final, oferecendo contraponto ao forte antagonismo entre agulha e linha e dando a deixa para a melancólica moral da história de Machado, que de certa maneira transborda para o filme. Mas se no conto machadiano o alfinete é a voz desencantada, que do alto da sua experiência tem a palavra final, dando à agulha sua lição de egoísmo e individualismo ("Faze como eu, que não abro caminho para ninguém. Onde me espetam, fico."), no filme ele é voz claramente dissonante, elemento perturbador a ser neutralizado. Não por acaso, sua entrada em cena é precedida de uma gargalhada algo demoníaca, e sua caracterização, com monóculo, gravata borboleta e bengala em forma de alfinete, não deixa dúvida de que se trata de figura afetada, acomodada e parasitária, antiexemplo do que quer que seja. Antiexemplo principalmente em relação a Machado de Assis, constituído como a figura exemplar, antípoda consumado do sucesso obtido pela acomodação e pela exploração do outro.

De fato, o filme apresenta Machado de Assis como alguém que descreve movimento ascendente a partir do trabalho, o que fica sugerido na enumeração das suas atividades e profissões - "Baleiro, coroinha, tipógrafo, revisor de provas, jornalista, funcionário público, tudo isto ele foi sucessivamente", diz o narrador. A justificativa dessa trajetória está na dedicação, na operosidade - características ressaltadas por Lúcia Miguel Pereira no seu estudo biográfico de 1936 e que a partir desse momento nunca mais serão descoladas da figura de Machado de Assis, reiteradamente caracterizado, inclusive pelos manuais escolares, como grande trabalhador, "grande operário das letras" e funcionário público exemplar. Se não são propriamente invenções, já que temos indícios e provas suficientes de que Machado de Assis foi bom funcionário e homem trabalhador, são reiterações inventadas durante o Estado Novo.

O escritor, ainda em vida transformado em medalhão, embora fosse recorrentemente tratado como figura de exceção, excêntrica e estrangeirada - grego, 
ático, francelho, inglês, gênio latino, tudo isso foi dito do escritor em vida e nas duas primeiras décadas do século XX -, era alçado à condição de figura exemplar, patrimônio e modelo da nacionalidade.

Para o processo da canonização oficial então em curso, ao qual o filme dá expressão visual, não falta nem mesmo a exibição das relíquias conservadas pela Academia Brasileira de Letras: a escrivaninha e a poltrona, o tinteiro e a pena, o pince$n e z$ - instrumentos de trabalho aos quais é acrescido o ramo do carvalho de Tasso, presente que Joaquim Nabuco enviara para Machado de Assis da Itália.

Constituía-se assim o "autor oficial", o ícone imobilizado nos retratos distribuídos pelas escolas de todo o país - os jornais de junho de 1939 vão dando conta das cerimônias de inauguração dos retratos de Machado de Assis nas várias escolas do Rio de Janeiro e do país $-{ }^{14}$ e cunhado nas moedas que trazem no anverso o busto de Machado e no reverso os 500 réis circundados por um ornamento em estilo marajoara, numa associação inequívoca do escritor ao nacionalismo oficial do Estado Novo.

A imagem do medalhão com traços aristocratizantes forjada no fim do Império e reforçada durante a vigência da primeira República dava lugar à figura do brasileiro exemplar, de origem popular, construída e fixada pelo Estado Novo.

Referências:

CANDIDO, Antonio. Esquema de Machado de Assis. In: . Vários escritos. São Paulo: Duas Cidades, 1970.

CÉSAR, Ana Cristina. Literatura não é documento. Funarte: Rio de Janeiro, 1980.

LEVINE, Robert M. Pai dos pobres? O Brasil e a era Vargas. São Paulo: Companhia das Letras, 2001.

MAUL, Carlos. "A transfiguração de um apólogo. Correio da Manhã, 13.07.1939.

\footnotetext{
${ }^{14}$ Há notícias de "programas cívico-literários", incluindo inaugurações de retratos de Machado em várias escolas, entre elas o Colégio Pedro II e o Colégio Andrews, o Colégio Brasil, a Casa do Estudante do Brasil, o Colégio Militar. "Por determinação do Dr. Costa Senna, diretor geral do Departamento de Educação do Estado do Rio, o centenário de Machado de Assis será comemorado hoje em todas as escolas públicas fluminenses, cujo vulto será exaltado, principalmente sob o aspecto de sua origem humilde, como exemplo a ser imitado por todas as crianças brasileiras." A Noite, Rio de Janeiro, s/d.
} 
SCHVARZMAN, Sheila. Humberto Mauro e as imagens do Brasil. São Paulo: Editora Unesp, 2004.

Hélio de Seixas Guimarães é professor na Universidade de São Paulo e pesquisador do CNPq; autor de Os leitores de Machado de Assis: o romance machadiano e o público de literatura no século 19 e A olhos vistos: uma iconografia de Machado de Assis, entre outros. E-mail: <hsg@usp.br>

Recebido: $13 / 09 / 2011$

Aprovado: 21/11/2011 